\title{
What factors affect the visibility of Argentinean publications in humanities and social sciences in Scopus? Some evidence beyond the geographic realm of research
}

\author{
Zaida Chinchilla-Rodríguez $\cdot$ Sandra Miguel $\cdot$ Félix de Moya-Anegón
}

Received: 10 March 2014/Published online: 29 August 2014

(C) Akadémiai Kiadó, Budapest, Hungary 2014

\begin{abstract}
Argentinás patterns of publication in the humanities and social sciences were studied for the period 2003-2012, using the Scopus database and distinguishing the geographic realm of the research. The results indicate that "topics of national scope" have grown and gained international visibility. They can be broadly characterized as having Spanish as the language of publication, and a marked preference for single authorship; in contrast, the publication of "global topics", not geographically limited, characteristically have English as the language of divulgation, and institutional collaboration is stronger and more consolidated. Citation is apparently not determined only by the geographic realm of research, but also by language of publication, co-authorship, and the profiles of the journals where published. These results could contribute to constructive reflection upon publishing policy. The existence of a community of journals that tolerates biased patterns may make researchers echo and perpetuate poor practices, constructing or adapting the channels of communication. Such results also prove useful as a point of reference when evaluation criteria are elaborated by scientific committees, as unsupervised promotion and evaluation patterns could become based on local or overly subjective precepts, disregarding the disciplinary practices of the international scientific community.
\end{abstract}

Z. Chinchilla-Rodríguez ( $\bowtie) \cdot F$. de Moya-Anegón

Consejo Superior de Investigaciones Científicas, Instituto de Políticas y Bienes Públicos, C/Albasanz, 26-28, Madrid 28037, Spain

e-mail: zaida.chinchilla@csic.es

F. de Moya-Anegón

e-mail: felix.demoya@csic.es

Z. Chinchilla-Rodríguez - S. Miguel · F. de Moya-Anegón

SCImago Research Group, Madrid, Spain

e-mail: sandra@fcnym.unlp.edu.ar

S. Miguel

Facultad de Humanidades y Ciencias de la Educación, Instituto de Investigaciones en Humanidades y Ciencias Sociales - IdIHCS (UNLP-CONICET), Universidad Nacional de La Plata, La Plata, Argentina 
Keywords Bibliometrics - Publication patterns - Citation - Scientific collaboration · Language of publication - Journals - Evaluation criteria $\cdot$ Argentina $\cdot$ Topics of national scope $\cdot$ Topics of global scope $\cdot$ Scopus

\section{Introduction}

The study of scientific communication explores various channels (formal and informal) used by researchers to divulge the results of their endeavors. Bibliometrics provides welldefined methods to approach scientific communication, assuming that the objects, actors, events and contexts involved in this activity are all entities that can be quantified (Borgman and Furner 2002).

The most formidable hurdle to scientific output by countries that do not belong to the main causeway - and by extension to the national journals where research is largely published-continues to be attaining levels of both academic and editorial quality that merit inclusion in the major international databases, and therefore increase visibility (Cetto and Hillerud 1995; Ochoa 2004; Miguel 2011). The recent aperture policies of Scopus and the Web of Science (WoS), towards indexing more and more regional journals, obeys a strategy of expansion that permits international communities to access contents with local perspectives or focused on topics of regional interest (Michels and Schmoch 2012). In this framework, the so-called humanities and social sciences play a highly relevant role, and their international visibility is growing at an impressive rate. Notwithstanding, some studies show that the aspiration of national journals to be indexed by international databases entails a new dilemma. When journal inclusion is achieved, a drop in the levels of impact of the country ensues (Gómez et al. 1995; Zitt et al. 1998; Luna and Collazo-Reyes 2007), because most journals are classified in the fourth quartile (Q4) in terms of impact.

Another imposing battlefield is collaboration. Signs from governmental and funding organisms are becoming very explicit: investment in research depends on collaboration and association. Financing should ensure high quality output, and collaboration means saving costs by sharing equipment and competences. Hence, the accreditation of research projects considers the configuration of teams of researchers, and the request for funding may demand the concurrence of researchers and groups from different institutions, regions and/ or countries. Some of these initiatives grew out of the Ibero-American Cooperation for Scientific and Technological Development Programme (Programa Iberoamericano de Cooperación en Ciencia y Tecnología para el Desarrollo, or CYTED), and the IberoAmerican Research Area (Espacio Iberoamericano del Conocimiento, EIC). This idea is no different from the premise underlying the Commission of the European Union's Lisbon Strategy, which identified knowledge as the grounds for economic competitiveness (Chinchilla et al. 2012a, b).

However, in some fields the quantification and qualification of science are systematically forgotten, and may even be penalized, especially in the processes of evaluating the results of activity; for instance, papers undersigned by various authors may be seen as a weakness instead of a strength (Gauffriau et al. 2007; Abramo and D'Angelo 2011; Fedderke 2013; RPCSD, 21 November 2013). ${ }^{1}$ There is a need to explore to what extent a

\footnotetext{
1 In Spain, the evaluation criteria in the realm of social sciences laid down by the Comision Nacional Evaluadora de la Actividad Investigadora (CNEAI) specify that the number of authors of a contribution should be justified by the subject matter, its complexity and its extension. In the case of Humanities: "Unless plainly justified by the complexity of the subject matter, the size of the corpus analyzed or the extensión and
} 
range of research funding-related decisions based on peer review actually corresponds with the array of objective measures of scholarly performance. Fedderke (2013) reports evidence that peer review is less likely to reward multi-authored research output than singleauthored output. In other words, claims that peer review mechanisms are based on an objective consideration of research impact are incompletely supported by the data. It is ironic that organisms in charge of financing emphasize collaboration, while generalized discredit is shown by the commissions that define evaluation criteria when joint research efforts are in fact assessed (Perianes et al. 2009).

The behavior of authors with regard to co-authorship also seems to be influenced by the target readership — national or international — of their articles. Those who publish in an international journal do so mostly through multiple authorship with foreign researchers, and receive more citations, unlike the trend of publication in national journals (Araujo et al. 2005; Fernández-Quijada et al. 2013). Meanwhile, the predominance of the Spanish language in articles published by Ibero-American journals in the humanities and social sciences has also been documented. The case of Spaińs journals is one good example (Osca and Haba 2005; Rodríguez and Giménez 2013). Further remarkable tendencies may be brought to light when the coverage of studies is derived based on international sources. Such is the case of Argentinean output within the decade 1990-2000 in the social sciences visible in the WoS (Molteni and Zulueta 2002).

One should bear in mind that the scientific activity of researchers, the relationships of collaboration established, the patterns of publication of their results and the citation of these publications by colleagues are all social activities. This means that the measures provided by bibliometrics are not the only indicators that might account for the results and impact of research. It follows that any measure used to gauge impact will also reflect social factors beyond the conventions or patterns of behavior of scientific output, which may be linked with the prestige of the author or of the institution where he/she works (Bornmann and Daniel 2008), among other factors. Still, bibliometrics do reflect the cognitive value and scientific influence of the knowledge generated, and therefore are valid indicators of potential utility in benefit of the scientific, technological, economic and social development of the countries. In short, indicators provide evidence of the conducts displayed by researchers of different disciplines in the realm of scientific communication.

\section{Objective and research questions}

This work focuses on the analysis of Argentinás scientific output in the humanities and social sciences in the period 2003-2012, as registered in the Scopus database. The main objective is to compare the patterns of publication, collaboration and impact according to the geographic scope of the research - that is, topics targeting national readership, and topics that reach beyond the national frontier. The behavior of both groups is analyzed and described regarding the variables: language of publication, indexes of collaboration, and citation. The research questions put forth are:

Footnote 1 continued

innovative nature of the contribution, the existence of more than one author can reduce the qualification assigned to it." (España 2013) 
1. Are there differences in the patterns of publication and collaboration among the work by Argentinean researchers who publish articles that deal with national research topics as opposed to other, broader topics?

2. What are the habits and behaviors governing collaboration, whether national or international, in both topic groups?

3. What elements comprise the networks of international collaboration for the two target groups of study?

4. Do the patterns of publication and collaboration have differential effects in terms of citation?

5. And What interest does such information have for the establishment of evaluation criteria by institutional and national policies?

It is hoped that the results will feed constructive debate about the research culture and corresponding editorial practices, to make them more uniform with regard to international standards, favoring better diffusion, visibility and impact of output. We also believe that our findings may constitute a useful point of reference for evaluating committees and editorial policy-makers at the national level, to eventually establish more suitable evaluation criteria.

\section{Materials and methods}

\section{Data source and search strategy}

The source of data used was Elsevieŕs international and multidisciplinary database Scopus. Its use is justified by the broad geographic and thematic coverage it affords (Moya et al. 2007). The study takes in the period 2003-2012, the document type being articles and reviews, and Argentina constituting the subject of study. The area of knowledge analyzed was the humanities and social sciences, which comprises: Arts and Humanities; Business, Management and Accounting; Decision Sciences; Economics, Econometrics and Finance; Psychology and Social Sciences. In turn, following the current classification of Scopus we took into account four major thematic areas: Life Sciences, Health Sciences, Physical Sciences, and Social Sciences and Humanities. This study is part of a major project aiming to analyze the patterns of publication according to the geographic scope of the research within these four thematic groups. Despite certain differences in the disciplinary patterns, which can be seen as a limitation of our methodology, a first approach involved reconsideration of the subject matter on the whole, as evaluation criteria are not established for disciplines, but rather for major subject areas. In future studies the analyses will be broken down by thematic categories having more output and impact in Argentinean science in the framework of these four major groups (as there are areas with very few documents) so as to study patterns and identify similarities and differences. Moreover, it is hoped that citation of the articles published in arts and humanities can be analyzed eventually. Although this output is very scarce to date, using the Scopus database such analysis will be possible, including posterior comparisons with other geographic domains.

Delimiting the geographic realm involved retrieving the records with at least one author who had included Argentina as the country of institutional affiliation (AffilCountry). After thus defining the information, two search strategies were established to obtain two separate groups of registered data. The first group contained recorded research whose geographic scope was Argentin*, determined by the presence of the name of the country or the name 
Table 1 Evolution of the numbers of documents by group

\begin{tabular}{lll}
\hline Year & $\begin{array}{l}\text { Topics of } \\
\text { national scope } \\
\text { ndoc }\end{array}$ & Other topics \\
\hline 2003 & 107 & ndoc \\
2004 & 123 & 117 \\
2005 & 104 & 136 \\
2006 & 120 & 153 \\
2007 & 177 & 165 \\
2008 & 198 & 158 \\
2009 & 278 & 308 \\
2010 & 372 & 409 \\
2011 & 414 & 446 \\
2012 & 491 & 507 \\
Total & 2,384 & 585 \\
\hline
\end{tabular}

of any province of Argentina in the field of title, keywords and/or abstract of the bibliographic register. The second group took in the remaining segment of the records, in which the name of the country (Argentina) or a province did not appear. Accordingly, the first group was identified as "Topics of National Scope", whereas the second was designated as "Other Topics".

The "topics of National Scope" were defined, for the purposes of this study, in view of the physical description or delimitation that the authors specify when they attribute the work geographically, either as a "national topic" or as a study "geographically situated". This grouping takes in both the works where Argentina is the only country included -even though it may be the object of comparison with other countries-while also embracing research on Argentinean persons, events, places, objects, etc. In "Other topics" or "Topics not geographically situated" the realm is understood to be the remaining set of publications by Argentinean authors in which there are no geographic terms of delimitation relative to Argentina in the title, keywords or abstract within the bibliographic registers.

To validate the classification of the records retrieved, two samples were taken, stratified by year, with 100 works each. By reading the abstract it was determined whether or not the documents pertained to the two established data sets in proportions of no less than $95.4 \%$ (that is, $95.4 \%$ of the sample records were pertinent). This validation methodology led us to resituate $4.6 \%$ of the documents of the group "topics of national scope" into "other topics" and $3.5 \%$ of the documents from "other topics" into "topics of national scope". Table 1 shows the volume of records retrieved for each set of data per year, once the records had been validated.

Bibliometric indicators and heliocentric networks of international collaboration

For each group of records, the following indicators were calculated:

1. Annual volume and evolution of output (ndoc) during the period studied

2. Annual volume and evolution of single authorship (ndoc signed by a single author) and multiple authorship (ndoc signed by two or more authors).

3. Annual volume, evolution and percentages of international collaboration (CI) and national collaboration $(\mathrm{CN})$. The ndoc in $\mathrm{CI}$ are those signed in collaboration with at least one author having affiliation with a foreign institution. The ndoc in $\mathrm{CN}$ are the 
ones signed by at least two authors, as long as they are only from Argentinean institutions. The ndoc in NC designates the ones signed by a single institution.

4. Evolution of the citations per document (citas/doc) by year, according to the type of collaboration (CI or $\mathrm{CN}$ ), number of authors and language of publication.

5. Citations per document in international collaboration. Two heliocentric networks were created (one for each thematic group) in which the international relations of Argentina with other countries are shown. These networks represent, on the one hand, the frequency of relations and their repercussions in terms of citations per document. The size of each node (country) is proportional to the percentage of documents in collaboration with that country. Its color denotes the membership of that country to a geographic region. Around the node orbit at a greater or lesser distance all those countries with which Argentina collaborates, and their relationship is represented with a line whose distance is inversely proportional to the impact. In this way, the countries closest to the center are the ones achieving a greater amount of citations per document, while the ones farthest away are the ones with the least impact. We can thus quickly identify the countries with which Argentina publishes more (greater size of node) and those with which it achieves greater international impact (closer to the center). Meanwhile, to compare the impact of the association with a given country, two concentric circles are represented, with the relative values of mean impact reached according to the type of collaboration. These circles are the national reference value of citation per document attained by the documents published in National Collaboration (blue) and International Collaboration (red). Thus we manage to situate those countries that contribute more or less citation according to their membership to each circle or to the periphery, and determine which are situated above or below the mean impact by type of collaboration (Chinchilla et al. 2010; Chinchilla et al. 2012a, b).

6. Evolution over time of the number of journals of the main Ibero-American producers indexed in Scopus. Distribution by quartiles according to the impact of the journals: the percentage of journals and of documents, and normalized impact by quartiles.

7. Impact/Normalized Citation, this being the relative number of citations received by each country, compared with the world mean for citations per document of the same type, year and category. It is calculated using the methodology "Item oriented field normalized citation score average" established by the Karolinska Institutet of Sweden (Rehn and Kronman 2008), by which citation values are normalized at the level of the individual article. The values (\%) show the relationship between the mean scientific impact of a country and the worldwide average on the whole, with a score of 1 . Therefore, an NI of 0.8 means that the country is cited $20 \%$ less than the world average; a score of 1.3 means it is cited $30 \%$ more than the world average. This indicator is used in Table 2 to compare the impact of countries regarding the position of journals by quartiles.

\section{Results}

The total volume of documents amounts to 5,368, of which $43.65 \%$ were found to pertain to the group "topics of national scope", while the remaining $56.65 \%$ would constitute "other topics". Analysis of the evolution reveals that the international presence and visibility of publications signed by Argentinean researchers when dealing with topics of national scope increases fivefold, though at a slower rate than the group of "other topics", except in 2007 (Fig. 1). This year presents a point of inflection that seems to be related with the entrance of 

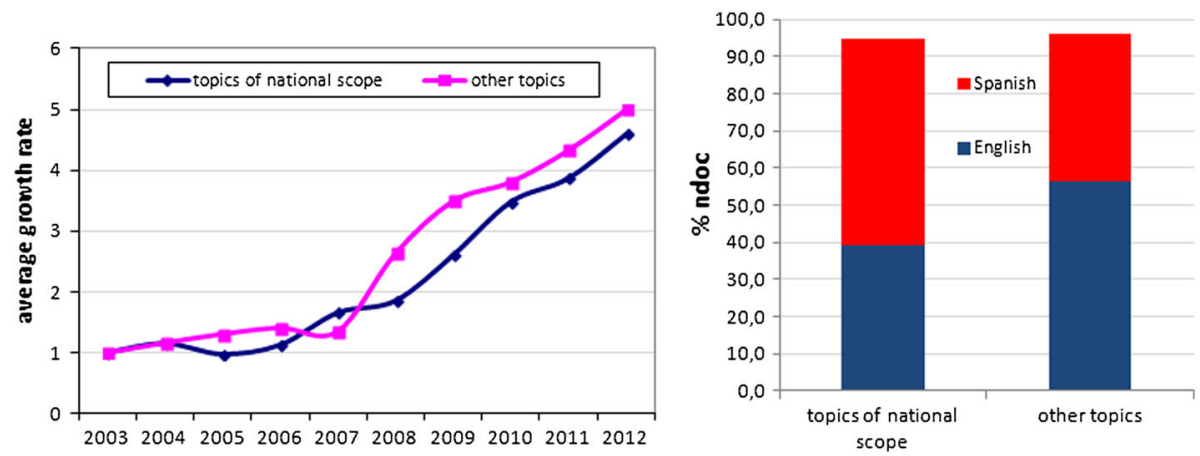

Fig. 1 Evolution of the rate of growth by groups and percentages by language of publication

a

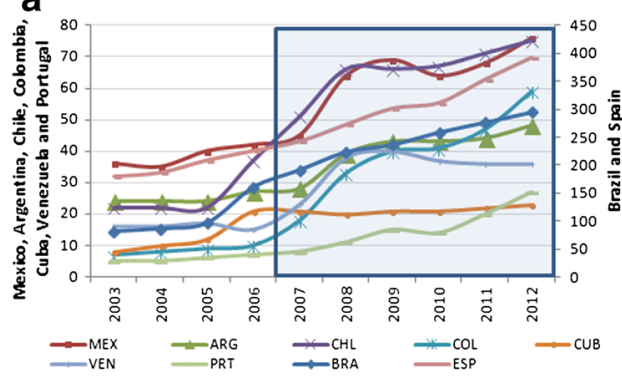

b

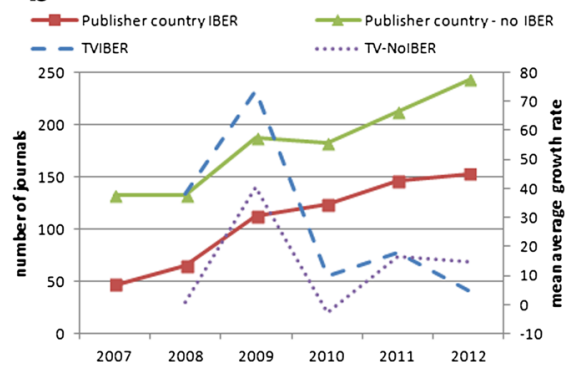

Fig. 2 a Evolution of indexed number of journals by country in Scopus (left). b Evolution of journals IBER and journals of other countries where publish the Argentinean researchers in social sciences and humanities (right)

journals in the Scopus database. Figure 2 (left) shows the evolution of journal entry involving the main Ibero-American producers. Brazil, Mexico and Chile underwent the greatest growth in the number of registered journals from 2005 onward. The rest of the countries, Argentina among them, present a significant increase after 2007. When the number of total journals publishing documents by Argentinean authors in the social sciences and humanities is analyzed, depending on the country of origin of the publisher - that is journals published in Iberoamerican countries versus journals published by any other country worldwide (Fig. 2 right) - the data reveal much more rapid growth in the number of Iberoamerican journals in which Argentinean authors publish after the year 2007. Thus the indexing of Iberoamerican journals in Scopus may be influenced by the growth of Argentinean output, although further study would be necessary to back up such a statement.

The language of publication in the case of the topics of national scope is mainly Spanish, with over $55 \%$ of documents, as opposed to $39 \%$ in English. However, the relationship is inverted when the group of "Other Topics" is analyzed (56.5\% in English and $40 \%$ in Spanish). In both cases, the contribution of languages other than Spanish and English is negligible.

Single versus multiple authorship

Another aspect to be highlighted is the evolution of the number of documents signed by a single author as opposed to those signed by more than one author, discerning between the 


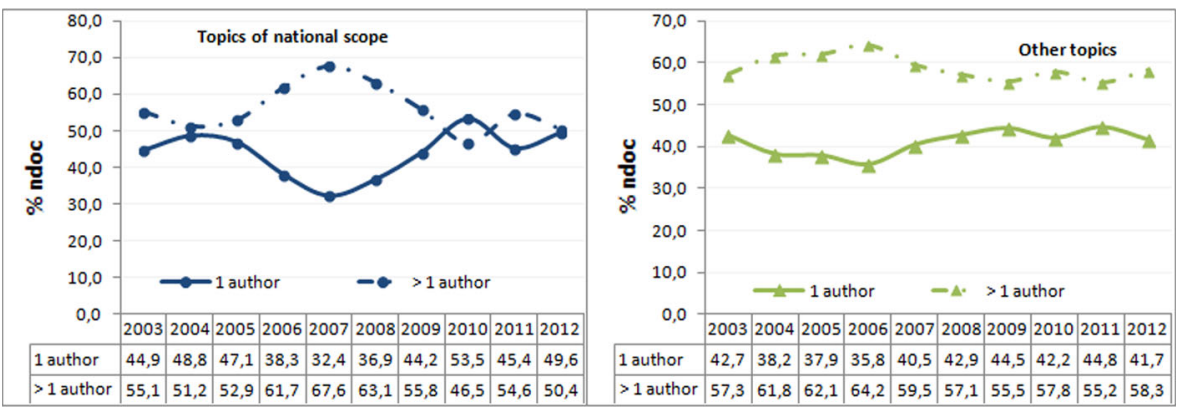

Fig. 3 Evolution of single authorship and co-authorship

two "topics" groups of documents. The proportion of articles signed in co-authorship is greater than that of a single author, in both cases. But a closer look shows certain important differences for the two groups. In topics of national scope the behavior is asymmetric, with many fluctuations. Up to the year 2007 single authorships are on the rise whereas coauthorships decline; later on the trend is reversed, to the point where at the end of the period, the proportions between single and multiple authorships are equivalent. In turn, in research with "Other Topics" the pattern is stable, with publication in collaboration prevailing over single authorship throughout the period (Fig. 3).

Despite Spanish being the outstanding language of publication for both groups, again there are diverse tendencies deserving mention. During the first years, Spanish-language publication for topics of national scope with single authorship drops in percentages to the point of being equal to those of English language between 2006 and 2007, a year in which they underwent noteworthy growth, becoming $80 \%$ of the total output. Notwithstanding, the evolution is quite different when output is co-authored, as until the year 2007 English is the main language $(70 \%)$ and as of 2008 there is a change in trend leading to equal percentages, with Spanish corresponding to nearly $60 \%$ of the production in recent years.

Regarding the research in "Other Topics", the main difference with respect to the first group is the proportion of articles/reviews in English with a single author or with multiple authors. Meanwhile, the first years of the period of study show percentages over $60 \%$ of the use of English in works with single authorship, yet at the end of the period the English language documents represent just $20 \%$ of the total. Nonetheless, the evolution of the documents signed by multiple authors shows a clear predominance of English early on (90\%), then a steady drop until the year 2007, when they stabilized at $70 \%$, until the end of the period (Figs. 4, 5).

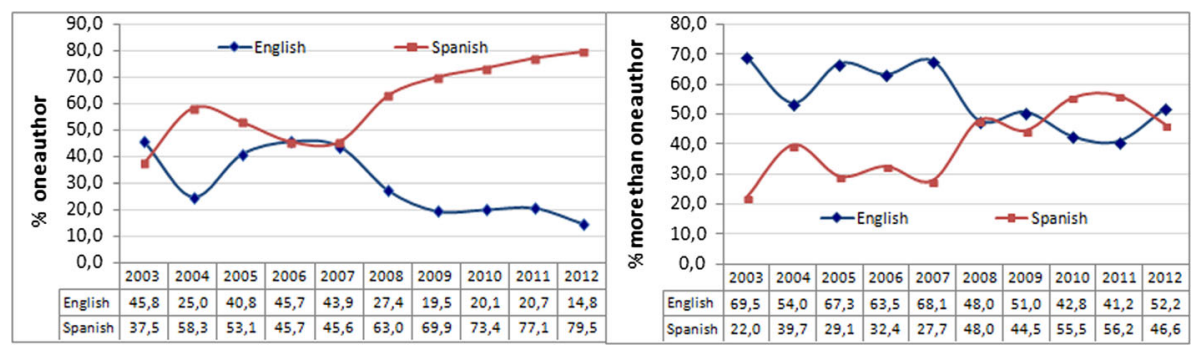

Fig. 4 Language of publication, by authorship, in topics of national scope 

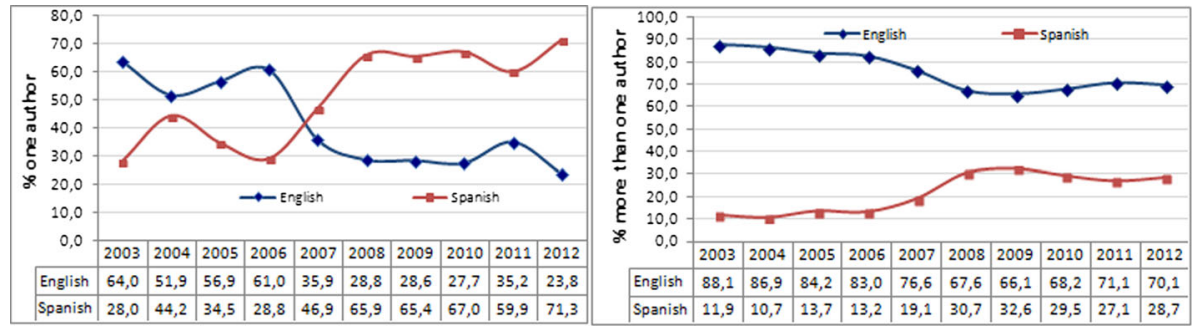

Fig. 5 Language of publication according to authorship/co-authorship in other topics

Patterns of collaboration and language of publication

The patterns of collaboration are vastly different for the two types of research topics. In both sets there is a great concentration of publications signed by authors affiliated to a single institution (no collaboration). Yet while the topics of national scope display no evident behavioral pattern, in the set of "Other Topics", an overt tendency to publish with national institutions increases up to the end of the period of study. This initial rise in national collaboration is accompanied by a decline in authorship stemming from a single institution, and in turn generates an increase in collaboration - not just national but also international collaboration (Fig. 6).

Remarkable patterns of international collaboration are detected in both groups studied. For topics of national scope, early on the rate of internationalization doubles, reaching $40 \%$ of output, and then it drops stabilizing at some $20 \%$ of output. This drop in international relations is accompanied by an increase in the national collaboration (and a drop in non-collaboration). However, the pattern that prevails is that of non-collaboration with other institutions. In "other topics", an interesting phenomenon is seen. In the early years, collaboration with foreign institutions amounts to nearly $40 \%$ of output, but after 2007 the panorama changes. A drop is evident, which is not accompanied by an increase in national collaboration. Notwithstanding, international participation after 2008 is present in over $50 \%$ of output.

When the language of publication is analyzed, bearing in mind the institutional relations and the geographic realm of the topics of research, again certain patterns stand out. The common denominator is the greater presence of English in international collaboration,

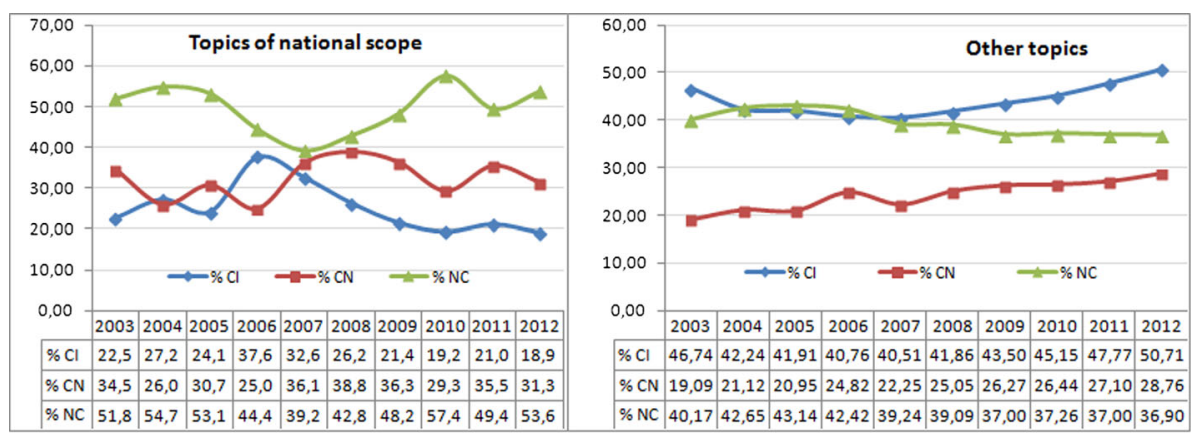

Fig. 6 Patterns of institutional collaboration 


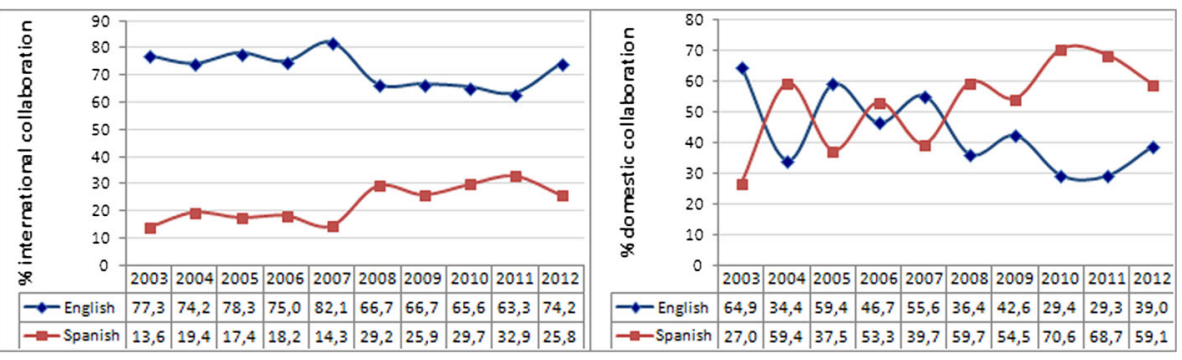

Fig. 7 Language of publication by patterns of collaboration in topics of national scope

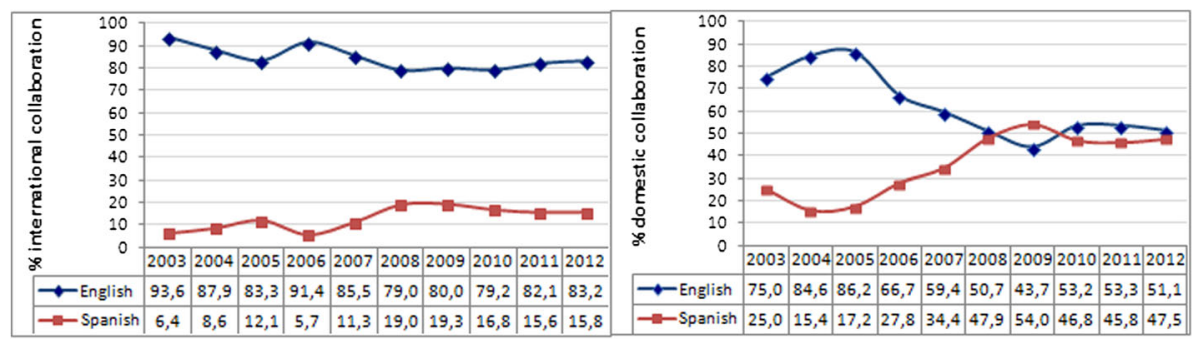

Fig. 8 Language of publication by patterns of collaboration in "Other Topics"

especially in the case of "Other Topics", and the tendency toward a relative decline that favors a slight increase in the output in Spanish from 2008 to 2011. The evolution of national collaboration in each language presents very different trends depending on the topic, although in both cases a rising trend is seen for English in more recent years. National collaboration in "Other Topics" presents a clear shift in trend over the period of study. A drop in the publication in English language is observed up to the year 2009, favoring the increase of output in Spanish; after 2010 the pattern is reversed and the use of English overshadows Spanish (Figs. 7, 8).

\section{Impact of output}

The patterns of publication and collaboration have repercussions for the impact of research. In the indicators analyzed, three important aspects are manifest: the topic of research, the patterns of collaboration, and the language of publication.

In the first case, the data reflect a much higher proportion of citations per document in nearly all the indicators for the group "Other Topics". In the second case, in both thematic realms, the publications in English language obtain on the average three and four times more citations per document than those published in the Spanish language (Table 2). In the temporal evolution some exceptions appear in the case of the works published in Spanish on national topics, which receive on the average slightly more citations per document than Spanish articles on "Other Topics" (Fig. 9).

In the second case, the publications undersigned by more than one author as opposed to single authorship have five times as many citations per document when it comes to topics of a national scope, and seven times as many for "Other Topics". Publications by multiple authors always harvest a greater impact, in both thematic divisions (Fig. 10). 
Table 2 Summary of citations per document for each indicator analyzed

\begin{tabular}{lll}
\hline Indicators & Topics of national scope & Other topics \\
\hline One author & 2.66 & 3.45 \\
Co-authorship & $10.60 \times 5$ & $20.64 \times 7$ \\
Domestic collaboration & $6.55 \times 3$ & $9.24 \times 3$ \\
International collaboration & $9.48 \times 4$ & $10.97 \times 3$ \\
Number of countries & 55 & 110 \\
English language & $7.20 \times 3$ & $9.12 \times 4$ \\
Spanish language & 2.46 & 2.06 \\
\hline
\end{tabular}
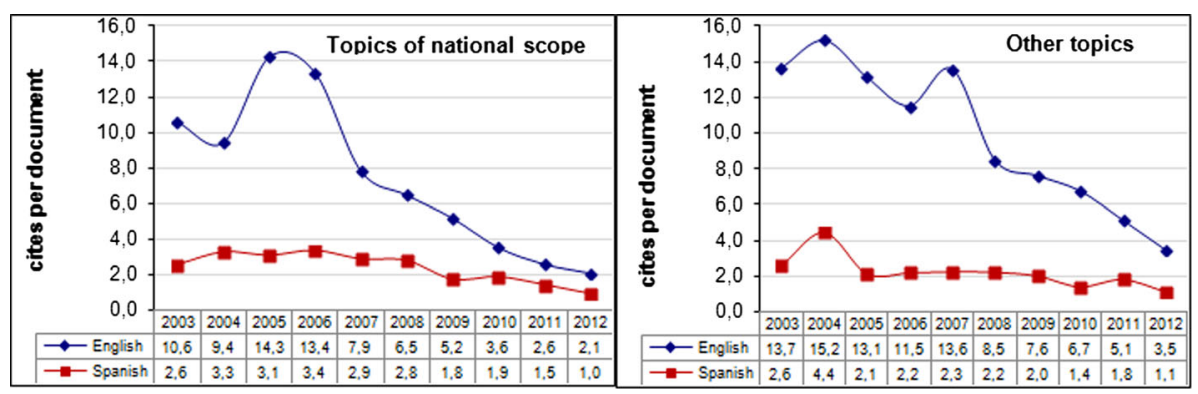

Fig. 9 Mean citations per document according to language of publication

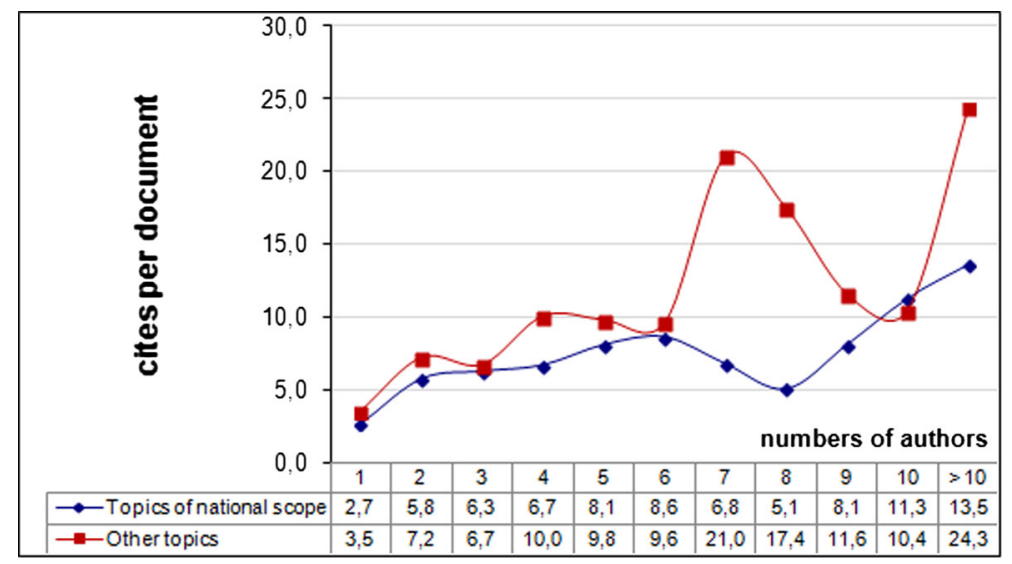

Fig. 10 Citations per document according to number of signing authors

The collaborative output by Argentinás institutions reaps, on average, three times as many citations than those obtained by the ones published by a single institution, and the institutional associations among the centers of different countries give rise to a greater average citation per document. This phenomenon is observed for both thematic groups, the impact being somewhat lesser when the topics are of national scope with regard to the group of "Other Topics". However, the most interesting relationship found here resides in the international authorship with respect to research impact, as seen in light of the axes in the two graphs of Fig. 11, regardless of the topic scope. 


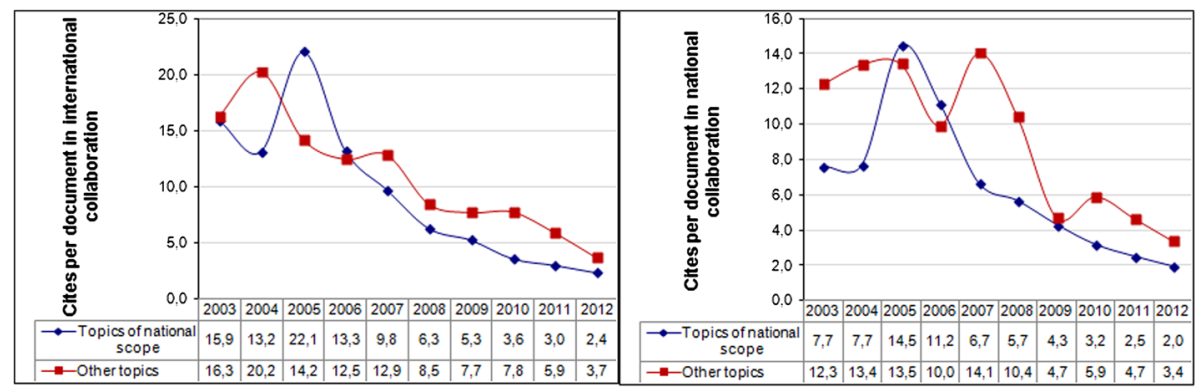

Fig. 11 Citations per document according to institutional collaboration

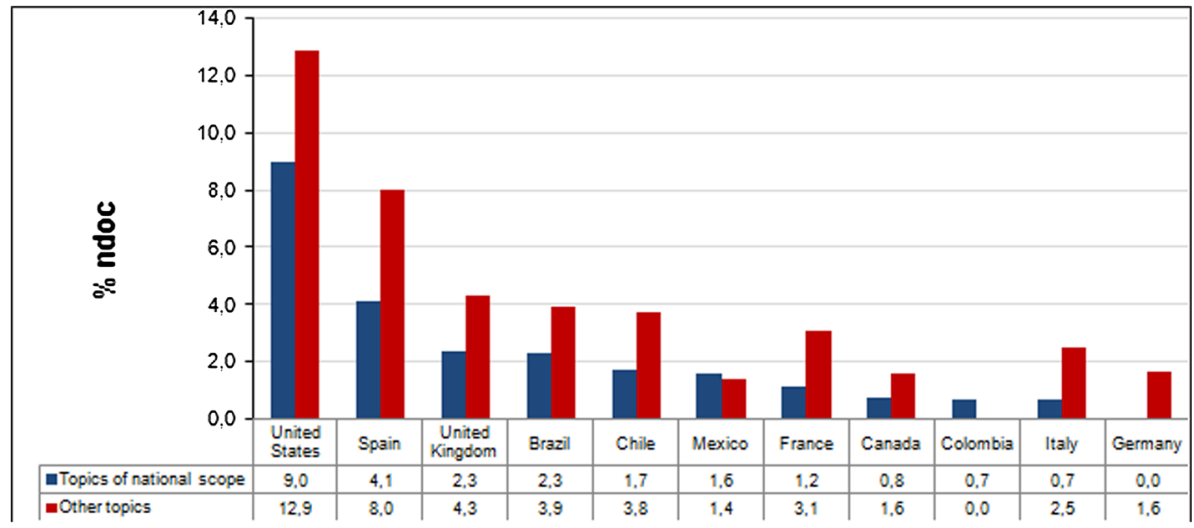

Fig. 12 Principal countries in international collaboration

Also noteworthy is the number of countries involved in the collaborative output, according to the research topic type. Figure 12 shows the ten countries having greater presence in both groups. For the most part they coincide; although Colombia appears in the top ten of national scope, in "Other Topics" we find Germany instead. This latter group shows that the number of countries is double, as is the percentage of documents published with them.

Networks of international collaboration

In order to calibrate the results of this collaboration in terms of the repercussions on the international scientific community and observe the impact with each country, we present two heliocentric networks of international collaboration with Argentina, depending on the thematic scope.

The networks show that, despite the international collaboration increasing the average citation, not all countries attain the same degree of impact. In the case of the topics of national scope (Fig. 13) collaboration with countries such as Panama, Cuba, Bolivia, Barbados, Peru, Bulgaria, Norway, Portugal and Turkey leads to a lesser citation than that obtained by means of national and international collaboration. For this reason, they are situated outside the orbit of the two concentric circles. Those that are situated in the central 


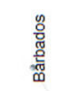

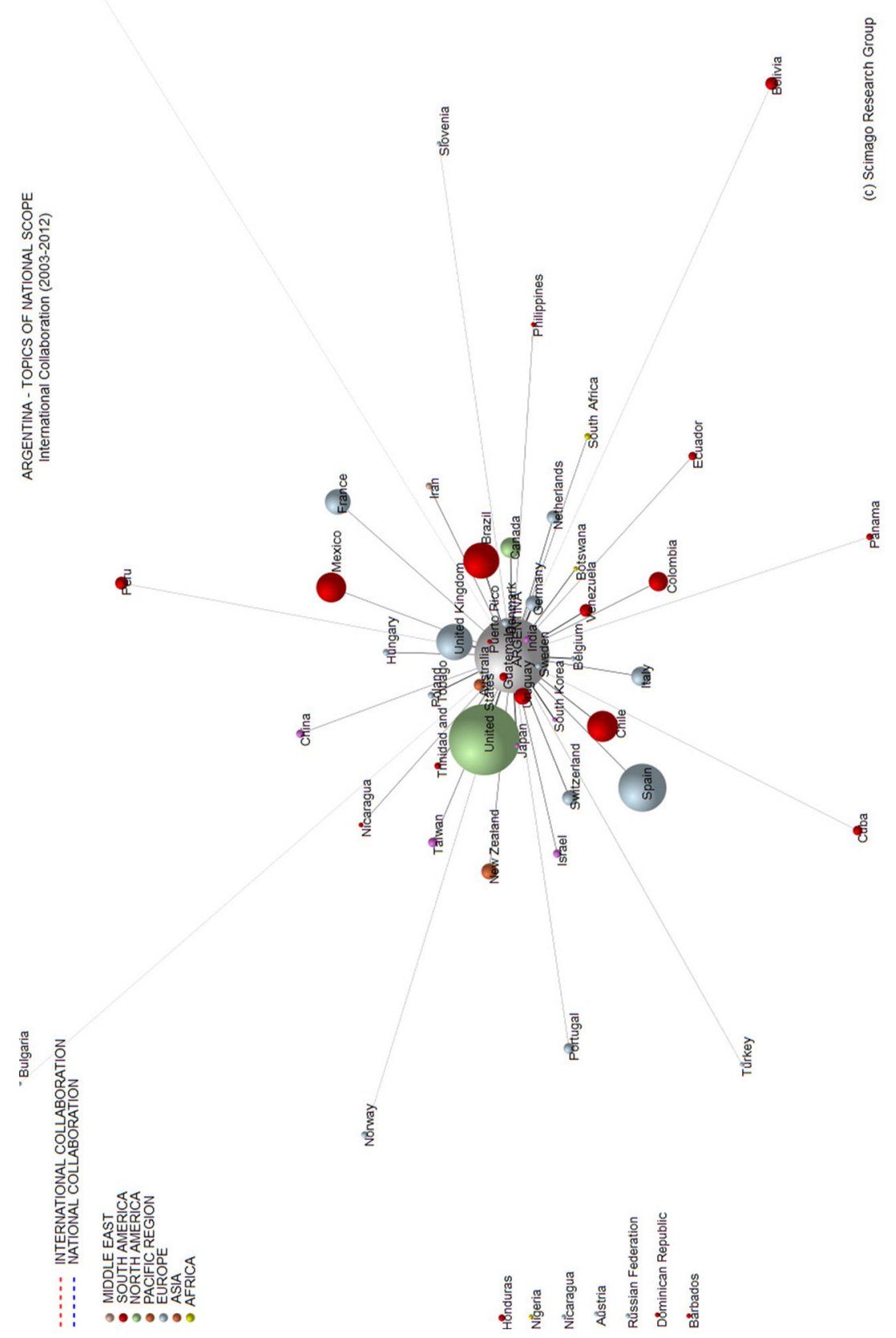

Fig. 13 Heliocentric network of international collaboration in topics of national scope 
orbit (citations per document received by production in international collaboration) are the ones that obtain greater impact. Outstanding among the great producers are the collaboration and the impact tied to the United Kingdom, the United States and Germany, as with these countries there is a great proportion of documents in collaboration. Yet there are also high citation rates per document with Uruguay, Australia, Puerto Rico, Denmark, Guatemala, India and Sweden, although the amount of documents is somewhat inferior.

International relations in "Other Topics" involve more countries and a greater frequency than the topics of national scope. Even though the countries with which there is more collaboration are the US, Spain, Brazil, the UK, Chile, Italy, France, Germany and Canada, citation per document is greater with the United Kingdom, Italy, Canada, Germany, Australia, Colombia, and Brazil. Citation per document is very near that obtained by Argentinean institutions in collaboration with the United States, Spain, France and Chile (Fig. 14).

Influence of the entry of national journals on the impact of output

Comparison of the visibility of international scientific output of some Latin American countries shows that the entry of national journals in the major international databases has two consequences or interpretations. First, the increased presence of research produced. On the other hand, a negative effect on the impact of the countrýs output is seen, mainly owing to the patterns of publication that predominate on the national level. Here the country's impact is measured taking into account the citation values normalized at the level of the individual article, and not citation per document. It means that the indicator used is relative, considering the number of citations received by each country as compared to the world mean for citations per document of the same type, year and category. The values, presented as percentages, express the relationship between the mean scientific impact of a country and the worldwide average on the whole, with a score of 1 . Therefore, an impact of 1.32 for Brazil in journals Q1 means that the country is cited $32 \%$ more than the world average; a score of 0.17 in Brazil in journals Q4 means it is cited $73 \%$ less than the world average.

Table 3 shows three significant results for each country. The first is the distribution by quartiles of the national journals that enter the database given their impact. The highest percentages are accumulated by journals of the third and fourth quartiles. Similarly, the percentage of documents published in national journals distributed by quartile, and therefore the incorporation of these journals, makes the impact lesser and lesser as they move down from the first (top) quartile.

In order to clarify which variables differentiate the two categories, a binary regression model was run. The results indicate that the model is significant, but has a very low predictive value $(\mathrm{r}$ square of Nagelkerke $=0.060$ ). The odds ratios show that the probability that topics of national scope would produce national collaboration versus no collaboration increased $37 \%$. However, they drop by $29 \%$ when it comes to international collaboration. That is, it is less probable that international collaboration is involved when geographically grounded topics are concerned. The origin of the journal (Iberoamerica or the rest of the world) is a determinant factor in the group of topics having a national scope - it nearly doubles the probability that the articles published therein deal with local topics as opposed to other topics. This variable is likewise highly correlated with the language of publication, as nearly all are published in the Spanish language. Meanwhile, as the number of citations increases, the probability that the articles deal with national topics decreases. 
II

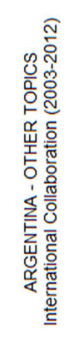
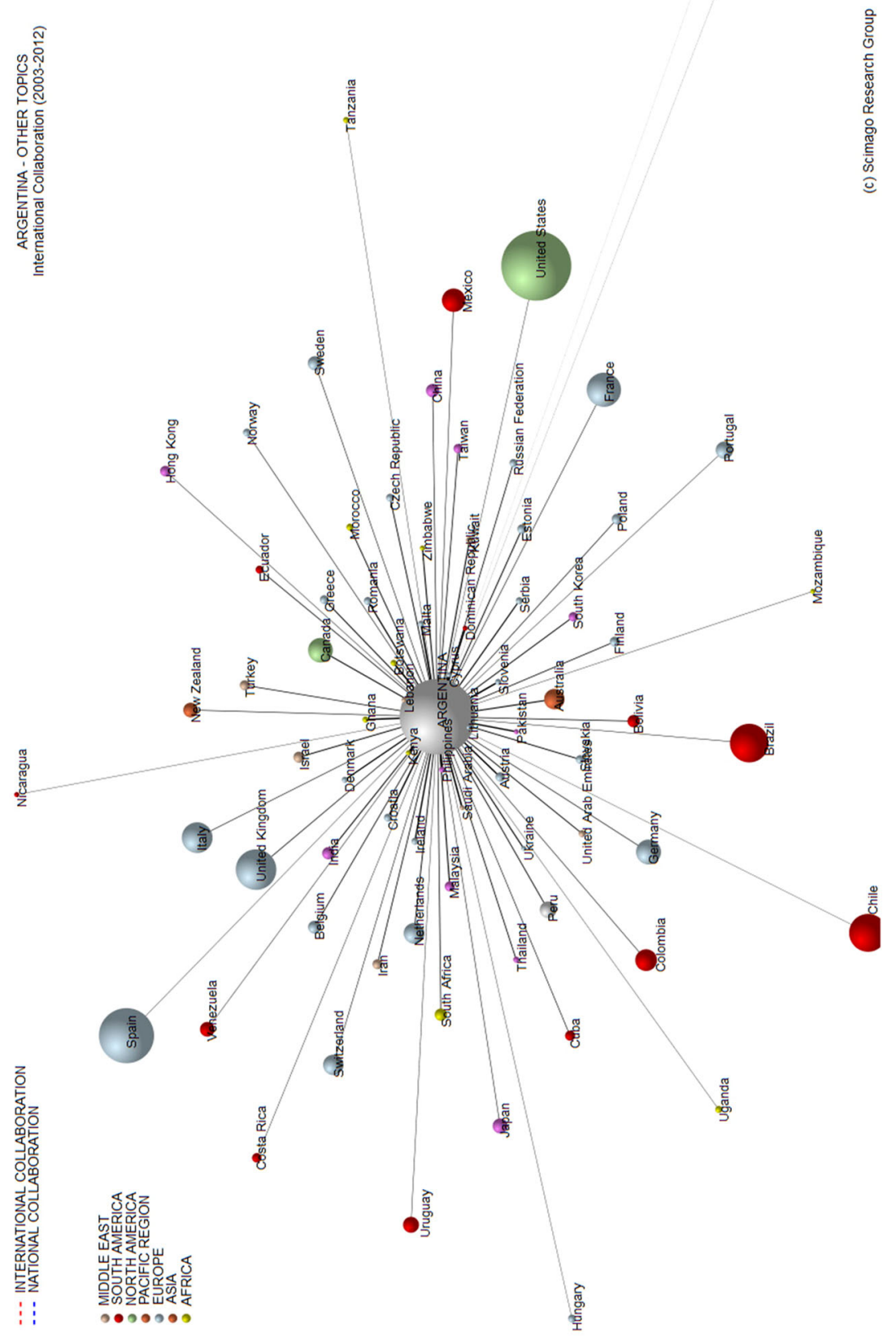

Fig. 14 Heliocentric network of international collaboration in "Other Topics" 
Table 3 Distribution by quartiles of the percentage of total journals, impact and national production

\begin{tabular}{|c|c|c|c|c|c|c|c|c|c|c|c|c|c|}
\hline \multirow[t]{2}{*}{ Country } & \multicolumn{5}{|c|}{ Journals } & \multicolumn{4}{|c|}{ Impact } & \multicolumn{4}{|c|}{$\%$ NDOC domestic journals } \\
\hline & Q1 & Q2 & Q3 & Q4 & $\%$ journ & Q1 & Q2 & Q3 & Q4 & Q1 & Q2 & Q3 & Q4 \\
\hline Brazil & 3.40 & 16.17 & 48.94 & 31.49 & 1.37 & 1.32 & 0.62 & 0.31 & 0.17 & 4.54 & 26.88 & 61.21 & 61.52 \\
\hline Mexico & 1.41 & 11.27 & 39.44 & 47.89 & 0.42 & 1.46 & 0.68 & 0.31 & 0.21 & 0.40 & 7.62 & 21.99 & 36.16 \\
\hline Argentina & 0.00 & 14.63 & 31.71 & 53.66 & 0.24 & 1.48 & 0.66 & 0.43 & 0.18 & 0.00 & 4.85 & 13.89 & 31.04 \\
\hline Chile & 4.35 & 17.39 & 43.48 & 34.78 & 0.40 & 1.49 & 0.70 & 0.41 & 0.28 & 1.00 & 20.42 & 38.55 & 52.60 \\
\hline Colombia & 0.00 & 2.70 & 24.32 & 72.97 & 0.22 & 1.55 & 0.74 & 0.34 & 0.12 & 0.00 & 6.57 & 22.23 & 56.72 \\
\hline Venezuela & 0.00 & 7.50 & 25.00 & 67.50 & 0.23 & 1.32 & 0.65 & 0.35 & 0.06 & 0.00 & 17.75 & 25.10 & 61.83 \\
\hline Cuba & 0.00 & 0.00 & 14.29 & 85.71 & 0.12 & 1.03 & 0.60 & 0.17 & 0.06 & 0.00 & 0.00 & 21.24 & 73.96 \\
\hline
\end{tabular}

Table 4 Binary regression model

\begin{tabular}{llllllll}
\hline & B & SE & Wald & gl & Sig. & Exp (B) \\
\hline Step 1 ${ }^{\mathrm{a}}$ & Collaboration & & & 70.603 & 2 & 0.047 & \\
& National collaboration & 0.316 & 0.068 & 21.569 & 1 & 0.000 & 1.372 \\
& International collaboration & -0.343 & 0.079 & 18.837 & 1 & 0.000 & 0.710 \\
& Publishing country & 0.683 & 0.078 & 76.229 & 1 & 0.000 & 1.979 \\
& Cities & -0.079 & 0.035 & 5.010 & 1 & 0.025 & 0.924 \\
& Language & -1.39 & 0.081 & 2.979 & 1 & 0.084 & 0.870 \\
& Constant & -0.356 & 0.064 & 31.059 & 1 & 0.000 & 0.700 \\
\hline
\end{tabular}

a Variables: Collaboration, Cites Publisher country, Language

Hence there is evidence that different patterns of communication can be found between the two groups, and that these have diverse effects upon the visibility of research (Table 4).

\section{Discussion and conclusions}

The relevance of research and the national or international scope of the subject matter approached constitute a growing concern in the definition of scientific research policies by all countries worldwide. In this context, underlying patterns of publication and collaboration, as well as the impact of output according to the geographic scope of research, may be seen as valuable aspects of scientific development that will help orient agendas for science, technology and innovation, while demonstrating the interest in certain "national" topics far beyond the domestic borders.

The results expounded here evidence a significant volume of research output from Argentina having international visibility, and that it multiplied by five during the period studied. This reflects the great expansion undergone by the humanities and social sciences in the international context of science. The relative presence of $44 \%$ of the topics of national scope stands as a very substantial proportion, and it may be interpreted as a positive aspect in the sense of the tensions among the local/international dimensions of the scientific practices of the peripheral countries (Kreimer 2000). To state that these topics are 
not of interest for the international community is not true, bearing in mind that this segment of publication includes papers signed in collaboration with authors from over 50 countries.

On the other hand, we observe more impact stemming from the research not merely exclusively focused on Argentinean topics when it is compared with the impact of more local topics. The increase in visibility linked with the volume of output may be affected by the entry of Iberoamerican journals in Scopus, whereas the greater impact of the more general topics would appear to be related with the patterns of publication and collaboration. Further analysis should be done to explore this phenomenon.

Within research into topics of national scope there is a predominance of Spanish as the language of publication, and a marked preference for single authorship as opposed to the patterns observed for the "Other Topic" group. Institutional collaboration is stronger in the first group, in which international collaborations are better consolidated. The output in Other Topics presents different behaviors for all the indicators, and the trends are much more stable over the time period of study. Thus, differences in impact are apparently not determined solely by the geographic realm and the thematic scope of research, but are also affected by the language of publication, single authorship versus collaboration, and the profiles of the journals where published; these results are in line with previous findings (Bornmann et al. 2012; Chinchilla et al. 2012b).

Single authorship versus co-authorship and national and international collaboration

In general, the average harvest of citations per document is higher in the case of coauthorship than when a single author is responsible for a document. The association with other authors, whether from domestic institutions or abroad, favors the impact of research (Katz and Martin 1997; Glänzel 2001). This positive relationship was also determined for the case of Argentina in other studies (Miguel 2008; Miguel and Moya 2009), although the tendency may vary depending on the country, sector or discipline in question (Leimu and Koricheva 2005; Glänzel et al. 2006; Engels et al. 2012; Ossenblok et al. 2014).

By no means does this indicate that Argentina will become an academic satellite depending on international collaboration for survival. Rather, as the national and international relations expand, there would be a greater proportion of documents led by local authors and research teams. Such leadership in the production of knowledge in collaboration is an indicator of the most genuine capacity of research from the institutions of a country (Moya et al. 2013), meaning the relevance of research topics can be tied to the priorities of institutional and national agendas, but not at the expense of excellence, nor implying a risk of lost autonomy. Analysis of collaboration is therefore of particular significance, because initiatives may often be the result of "research-for-aid" arrangements, generally based on North-South asymmetries (Bonfiglioli and Mari 2000). Over the years, however, collaboration for mutual benefit and excellence has gained increasing acceptance, with "partner" selection progressively becoming a strategic priority to enhance one's own production. In this context, a key prerequisite for the design of regional collaboration policies is the determination of how Latin American partners attain higher research potential (more and better results). This points to the benefits of collaboration in research involving a specific country or institution (Lancho et al. 2012; Chinchilla et al. 2012a; Guerrero et al. 2013). Although collaboration is an added value that favors an increase in individual capacities, and by extension that of the participating institutions, there is likewise a need to calibrate the results of such collaboration.

These findings are also highly relevant when designing criteria for evaluating scientific efforts. In the case of Argentina and its agendas and national evaluation commissions, it is 
remarkable that the empirical evidence demonstrating the progressively greater impact of output when co-authorship and or inter-institutional collaboration is involved has not led to criteria based on the performance results of scientific production as in other countries. Instead, collaboration is penalized to a certain extent, the end effect being to reward production by a single author. It will be interesting to further explore the foundations on which evaluating commissions are based.

\section{Language of publication}

The language of publication plays an important role in the comparative evaluation of national scientific systems. This is because the non-English language journals reach a level of impact considerably lower than those published in English (Egghe and Rousseau 2000). We believe that this has more to do with idiomatic capacities than with the scope or potential interest of the topics approached. Publication in the Spanish language reduces the community of readers, even though the work may be of great scientific interest. The fact that rigorous research output is not read simply because of language constraints means that the potential number of readers in the Spanish-speaking community is more determinant for international visibility than being indexed in the worlds largest database. It is not an isolated instance; nor is it characteristic of Latin American countries overall. It affects any country that is non-English speaking, as previous studies have come to demonstrate (Van Leeuwen et al. 2001). In the case of Argentina, this phenomenon occurs systematically, and the advisory commissions involved in elaborating criteria for the evaluation of scientific output moreover encourage publication in Spanish in the area of social sciences and the humanities ${ }^{2}$ evoking arguments that do not appear to be based on objective data such as those presented in this study.

National journals and influence on the impact of output

The phenomenon of dropping impact would be directly related with the journals chosen for publication, and it points to the paradox of inclusion in national journals in the major international databases as a factor making the impact of the country (and/or discipline) decline considerably; national output recently incorporated implies a series of patterns of publication and collaboration that are not uniform with international standards (Gómez et al. 1995; Zitt et al. 1998; Luna and Collazo-Reyes 2007). The influence of entering journals publishing most articles in Spanish and work by a single author configures patterns described by Molteni and Zulueta (2002) in studies of the previous decade.

This exceptional finding has to do with the transition from a national model to a transnational one. Such is the case of the countries whose coverage has increased to a great extent in recent years in international databases. The unprecedented inclusion of numerous journals in Scopus and WoS has been analyzed by several authors, who make manifest that this increase can be seen as part of a policy of expansion in the coverage of the main databases, and that in countries such as Brazil and Mexico it is moreover affected by an increase in the number of researchers (Leta 2011; Collazo-Reyes 2014). The Latin American journals of recent incorporation may have certain endogamic practices. In other

\footnotetext{
${ }^{2}$ In Argentina, for the case of Social Sciences and the Humanities there exists a preliminary document for evaluation criteria that can be consulted at: http://www.ceil-conicet.gov.ar/divulgacion/articulo-del-mes/criteriosde-evaluacion-de-la-produccion-cientifica-de-las-humanidades-y-ciencias-sociales-ciecehcs-comisioninterinstitucional-de-elaboracion-de-criterios-de-evaluacion-para-las-humanidades-y-cie/.
} 
words, their editorial committees may favor publishing articles by authors of the same country, leading to a high level of self-citation and in the same (national) language. Indeed, the lowest impact levels are positively correlated with high percentages of self-citation and publication in the national tongue (Collazo-Reyes et al. 2008; Collazo-Reyes 2014). This happens both in Thomson Reuters and in Scopus (Santa and Herrero 2010).

Improving the quality of journals is not simply a matter of time. There is a need for changes in habits - from editorial policy to certain research conducts (Collazo-Reyes 2014). The existence of a community of journals that tolerates unhealthy publication patterns eventually makes researchers get accustomed to this means of operating. And to some extent, the scientific community echoes and perpetuates poor practices, constructing or adapting the channels of divulgation. For instance, it is not enough to index journals if the international scientific community does not read Spanish, or participate in the research itself.

We must not lose sight of output as a crucial step in the process of internationalizing (and eventually internalizing) knowledge. The uniform acceptance of proper patterns of publication is a means to this end. Patterns of publication are more than the simple addition of local journals to vast data bases. There is much at stake. It is not just a matter of avoiding publication in a countrýs own journals, or neglecting topics of local relevance or national scope, because that would dissuade one from the objective of indexing in international databases. What we have here is a need to look over editorial policies and output patterns, because in any case being indexed in international databases increases visibility and the probability of being cited by a broader audience.

\section{Recommendations/implications}

The results of this study provide relevant information regarding diverse patterns of publication that stem from the geographic realm of research, and also have to do with the influence of national journals in the international impact of output. While we present the situation of Argentina here, the methodology described could be applied to other geographic or institutional domains.

The choice of Argentina as the case of study owes mainly to the fact that since 2003 their public policies for science, technology and innovation have placed special emphasis on complementing the traditional strategy of promoting research by disciplines, in turn fomenting the production of knowledge oriented towards national topics, whose main axis resides in the problems and opportunities in society and in the productive medium (MINCYT 2006). In parallel, the Ministerio de Ciencia, Tecnología e Innovación Productiva has put out a call for inter-institutional assessment committees to review the criteria for evaluating scientific/technological staff and scientific output. Along these lines, we hold that bibliometric studies supply tangible, objective information about the behavioral patterns followed by the different disciplines and countries, when confronting and appraising opportunities. The present study signals particular strengths and weaknesses and may serve to indicate and implement more suitable measures. A lack of this type of information when elaborating criteria for the promotion and evaluation of science in the different scientific systems worldwide could give rise to patterns based on local precepts and subjective biases totally unrelated to the disciplinary practices of the international scientific community. In the face of revising editorial policy of scientific journals, and in designing evaluation criteria for research, this paper underlines the need to reflect upon the value of bibliometric indicators to provide empirical evidence of the effects of sound 
communication practices, and that a shift in editorial habits would help scientific output attain more reasonable levels of visibility.

We stand at a crossroads of present-day technological advances, an emphasis on collaborative divulgation, possibilities of diffusion and visibility through electronic publications, and open access advocated to maximize the impact of research (Bernal 2013). This is the point where strategies must be questioned, and the practices underlying publication and collaboration brought into clear view. Evaluation criteria favor an increasing visibility of the social sciences, following regional and international standards of communication. Reflection and constructive debate of such matters are urgent for the research culture and for the scientific and editorial policies of very diverse countries and disciplines. The core of such discussion would not only bear upon our field, but also prove pertinent beyond, especially in circles where decisions are made regarding the design of evaluation systems in light of the overriding patterns of scientific communication.

Acknowledgments This work was made possible through financing by the Project PICT-2011-2183 "Argentina como objeto de estudio en la producción científica con visibilidad regional e internacional. Una aproximación al estudio del dominio temático argentino" funded by the Fondo para la Investigación Científica y Tecnológica (FONCYT) of Argentina. The authors appreciate the comments of the reviewers, which served to improve the quality and clarity of the manuscript, as well as support in the statistical analysis of data offered by José Manuel Rojo (CSIC-UAE), and translating/editing of the manuscript by Jean Sanders.

\section{References}

Abramo, G., \& D’ Angelo, C. A. (2011). Evaluating research: From informed peer review to bibliometrics. Scientometrics, 87(3), 499-514.

Araujo-Ruíz, J. A., Torricella-Morales, R. G., Van Hooydonk, G., \& Arencibia-Jorge, R. (2005). Cuban scientific articles in ISI citation indexes and CubaCiencias databases (1988-2003). Scientometrics, 65(2), 161-171.

Bernal, I. (2013). Open access and the changing landscape of research impact indicators: New roles for repositories. Publications, 1(2), 57-77.

Bonfiglioli, A., \& Mari, E. (2000). La cooperación científico-tecnológica entre la Unión Europea y América Latina: El actual contexto internacional y el Programa Marco de la Unión Europea. Revista REDES, Buenos Aires, Universidad Nacional de Quilmes, 7(15), 183-208.

Borgman, C. L., \& Furner, J. (2002). Scholarly communication and bibliometrics. Annual Review of Information Science and Technology, 36(1), 3-72.

Bornmann, L., \& Daniel, H. D. (2008). What do citation counts measure? A review of studies on citing behavior. Journal of Documentation, 64(1), 45-80.

Bornmann, L., Schier, H., Marx, W., \& Daniel, H. (2012). What factors determine citation counts of publications in chemistry besides their quality? Journal of Informetrics, 6(1), 11-18.

Cetto, A. M., \& Hillerud, K. I. (1995). Publicaciones científicas en América Latina. México: Fondo de Cultura Económica.

Chinchilla-Rodríguez, Z., Benavent-Pérez, M., Miguel, S., \& Moya-Anegón, F. (2012a). International collaboration in medical research in Latin America and the Caribbean (2003-2007). Journal of the American Society for Information Science and Technology, 63(11), 2223-2238.

Chinchilla-Rodríguez, Z., López-Illescas, C., \& Moya-Anegón, F. (2012b). Biomedical scientific publication patterns in the Scopus database: A case study of Andalusia, Spain. ACIMED: Revista Cubana de Información en Ciencias de la Salud, 23(3), 219-237.

Chinchilla-Rodríguez, Z., Vargas-Quesada, B., Hassan-Montero, Y., González-Molina, A., \& Moya-Anegón, F. (2010). New approach to the visualization of international scientific collaboration. Information Visualization, 9(4), 277-287.

Collazo-Reyes, F. (2014). Growth of the number of indexed journals of Latin America and the Caribbean: The effect on the impact of each country. Scientometrics, 98, 197-209. 
Collazo-Reyes, F., Luna-Morales, M. E., Russell, J. M., \& Pérez-Angón, M. A. (2008). Publication and citation patterns of Latin American and Caribbean journals in the SCI and SSCI from 1995 to 2004. Scientometrics, 75(1), 145-161.

Egghe, L., \& Rousseau, R. (2000). Partial orders and measures for language preferences. Journal of the American Society for Information Science, 51(12), 1123-1130.

Engels, T. C. E., Ossenblok, T. L. B., \& Spruyt, E. H. J. (2012). Changing publication patterns in the social sciences and humanities, 2000-2009. Scientometrics, 93(2), 373-390.

España, Ministerio de Educación, Cultura y Deporte. Resolución de 15 de noviembre de (2013). de la Comisión Nacional Evaluadora de la Actividad Investigadora, por la que se publican los criterios específicos aprobados para cada uno de los campos de evaluación. Boletín Oficial del Estado, 21 de noviembre de 2013, núm. 279, 92880-92893.

Fedderke, J. W. (2013). The objectivity of national research foundation peer review in South Africa assessment against bibliometric indexes. Scientometrics, 97(2), 177-206.

Fernández-Quijada, D., Masip, P., \& Bergillos, I. (2013). El precio de la internacionalidad: La dualidad en los patrones de publicación de los investigadores españoles en comunicación. Revista Española de Documentación Científica, 36(2), 1-19.

Gauffriau, M., Larsen, P. O., \& Maye, I. (2007). Publication, cooperation and productivity measures in scientific research. Scientometrics, 73(2), 175-214.

Glänzel, W. (2001). National characteristics in International scientific Co-Authorship relations. Scientometrics, 51(1), 69-115.

Glänzel, W., Debackere, K., Thijs, B., \& Schubert, A. (2006). A concise review on the role of author selfcitations in information science, bibliometrics and science policy. Scientometrics, 67(2), 263-277.

Gómez, I., Fernández, M. T., Zulueta, M. A., \& Camí, J. (1995). Analysis of biomedical research in Spain. Research Policy, 24(3), 459-471.

Guerrero Bote, V. P., Olmeda-Gómez, C., \& Moya-Anegón, F. (2013). Quantifying the benefits of international scientific collaboration. Journal of the American Society for Information Science and Technology, 64(2), 392-404.

Katz, J. S., \& Martin, B. R. (1997). What is research collaboration? Research Policy, 26(1), 1-18.

Kreimer, P. (2000). Ciencia y periferia: Una lectura sociológica. In: M. Monserrat (Ed.), La ciencia en la Argentina entre siglos. Textos, contextos e instituciones (pp. 187-200). Buenos Aires: Manantial.

Lancho-Barrantes, B. S., Guerrero-Bote, V. P., Chinchilla-Rodríguez, Z., \& Moya-Anegón, F. (2012). Citation flows in the zones of influence of scientific collaborations. Journal of the American Society for Information Science and Technology, 63(3), 481-489.

Leimu, R., \& Koricheva, J. (2005). What determines the citation frequency of ecological papers? Trends in Ecology \& Evolution, 20(1), 28-32.

Leta, J. (2011). Growth of Brazilian science: A real internationalization or a matter of databases'coverage? In E. Noyons, P. Ngulube, \& J. Leta (Eds.), Proceedings of 13th international conference of the international society for scientometrics and informetrics (pp. 392-408). Durban: ISSI, Leiden University and University of Zululand.

Luna-Morales, M. E., \& Collazo-Reyes, F. (2007). Análisis histórico bibliométrico de las revistas latinoamericanas y caribeñas en los índices de la ciencia internacional 1961-2005. Revista Española de Documentación Científica, 30(4), 523-543.

Michels, C., \& Schmoch, U. (2012). The growth of science and database coverage. Scientometrics, 93(3), 831-846.

Miguel, S. (2008). Aproximación cienciométrica al análisis y visualización del dominio científico argentino, 1990-2005. Granada: Universidad de Granada.

Miguel, S. (2011). Revistas y producción científica de América Latina y el Caribe: Su visibilidad en SciELO, RedALyC y SCOPUS. Revista Interamericana de Bibliotecología, 34(2), 187-199.

Miguel, S., \& Moya-Anegón, F. (2009). La ciencia argentina bajo la lupa de los indicadores cienciométricos: Una mirada crítica de la realidad científica argentina. La Plata: Ediciones Al Margen.

Molteni, V., \& Zulueta, M. A. (2002). Análisis de la visibilidad internacional de la producción científica argentina en las bases de datos Social Sciences Citation Index y Arts and Humanities Citation Index en la década de 1990-2000: Estudio bibliométrico. Revista Española de Documentación Científica, 25(4), $455-465$.

Moya-Anegón, F., Chinchilla-Rodríguez, Z., Vargas-Quesada, B., Corera-Álvarez, E., Muñoz-Fernández, F. J., \& González-Molina, A. (2007). Coverage analysis of Scopus: A journal metric approach. Scientometrics, 73(1), 53-78.

Moya-Anegón, F., Guerrero-Bote, V., Bormann, L., \& Moed, H. (2013). The research guarantors of scientific papers and the output counting: A promising new approach. Scientometrics, 97(2), 421-434. 
Ochoa-Henríquez, H. (2004). Visibilidad: El reto de las revistas científicas latinoamericanas. OpciónUniversidad De Zulia, 20(43), 162-168.

Osca Lluch, J., \& Haba, J. (2005). Dissemination of Spanish social sciences and humanities journals. Journal of Information Science, 31(3), 229-236.

Ossenblok, T. L. B., Verleysen, F. T., \& Engels, T. C. E. (2014). Coauthorship of journal articles and book chapters in the social sciences and humanities (2000-2010). Journal of the Association for Information Science and Technology, doi:10.1002/asi.

Perianes-Rodríguez, A., Chinchilla-Rodríguez, Z., Vargas-Quesada, B., Olmeda-Gómez, C., \& MoyaAnegón, F. (2009). Synthetic hybrid indicators based on scientific collaboration to quantify and evaluate individual research results. Journal of Informetrics, 3(2), 91-101.

Rehn, C., \& Kronman, U. (2008). Bibliometric handbook for Karolinska Institutet. Karolinska Institutet University Library. Version 1.05 .

Rodríguez-Yunta, L., \& Giménez-Toledo, E. (2013). Fusión, coedición o reestructuración de revistas científicas en humanidades y ciencias sociales. El profesional de la Información, 22(1), 36-45.

Santa, S., \& Herrero, V. (2010). Cobertura de la ciencia de América Latina y el Caribe en Scopus vs Web of Science. Investigación Bibliotecológica, 24(52), 13-27.

Van Leeuwen, T. N., Moed, H. F., Tijssen, R. J. W., Visser, M. S., \& Van Raan, A. F. J. (2001). Language biases in the coverage of the Science Citation Index and its consequences for international comparisons of national research performance. Scientometrics, 51(1), 335-346.

Zitt, M., Perrot, F., \& Barré, R. (1998). The transition from "National" to "Transnational" model and related measures of countries' performance. Journal of the American Society for Information Science, 49(1), 30-42. 